\title{
Penerapan Model Modified Find Someone Who dan Quiz-Quiz Trade untuk Meningkatkan Keterampilan Sosial Siswa Sekolah Dasar
}

\author{
Yenny Fardilla $^{1}$, Budi Eko Soetjipto ${ }^{2}$, I Made Suardana ${ }^{3}$ \\ ${ }^{1}$ Pendidikan Dasar-Universitas Negeri Malang \\ ${ }^{2}$ Manajemen-Universitas Negeri Malang \\ ${ }^{3}$ Pendidikan Matematika-Universtas Negeri Malang
}

\begin{tabular}{l}
\hline \hline INFO ARTIKEL \\
\hline Riwayat Artikel: \\
Diterima: $18-07-2019$ \\
Disetujui: $16-01-2020$ \\
\hline
\end{tabular}

Kata kunci:

modified find someone who; quiz-quiz trade;

social skills;

modified find someone who;

quiz-quiz trade;

keterampilan sosial

\author{
Alamat Korespondensi: \\ Yenny Fardilla \\ Pendidikan Dasar \\ Universitas Negeri Malang \\ Jalan Semarang 5 Malang \\ E-mail: yennyms16@gmail.com
}

\section{ABSTRAK}

Abstract: The purpose of this study is to improve social skills of fifth grade students through the application of the Modified Find Someone Who dan Quiz-Quiz Trade Models. This type of research uses a type of classroom action research. The research subjects were fifth grade students at Sumbersari 1 Malang Primary School. Data collection of students social skills using observation and questionnaires. The results of this study indicate that the Modified Find Someone Who and the Quiz-Quiz Trade models can improve students' social skills. This can be proven by the increase in the observation results of the students' social skills in the first cycle reaching $76.2 \%$ and the second cycle reaching $84.5 \%$. The results of the students social skills questionnaire in the first cycle reached $81.0 \%$ and increased in the second cycle reached $85.2 \%$.

\begin{abstract}
Abstrak: Tujuan dari penelitian ini adalah untuk meningkatkan keterampilan sosial siswa kelas V melalui penerapan model Modified Find Someone Who dan Quiz-Quiz Trade. Jenis penelitian ini menggunakan jenis Penelitian Tindakan Kelas. Subjek penelitian adalah siswa kelas V di SDN Sumbersari 1 Malang. Pengumpulan data keterampilan sosial siswa menggunakan observasi dan angket. Hasil penelitian ini menunjukkan bahwa model Modified Find Someone Who dan Quiz-Quiz Trade dapat meningkatkan keterampilan sosial siswa. Hal tersebut dapat dibuktikan dengan meningkatnya hasil observasi keterampilan sosial siswa pada siklus I mencapai $76.2 \%$ dan siklus II mencapai $84,5 \%$. Hasil angket keterampilan sosial siswa pada siklus I mencapai $81,0 \%$ dan meningkat pada siklus II mencapai $85,2 \%$.
\end{abstract}

Permasalahan yang ditemukan selama pengamatan proses pembelajaran di kelas V SDN Sumbersari 1 Malang, yaitu (1) saat guru menjelaskan materi dan memberikan instruksi, 15 dari 32 siswa tidak mendengarkan guru secara seksama, (2) siswa masih terlihat pasif saat bekerja secara kooperatif, hanya tiga dari tujuh orang siswa dalam setiap kelompok yang bekerja aktif saat berdiskusi dan mengerjakan tugas, empat siswa lainnya tidak ikut membantu, (3) pada saat presentasi, siswa merasa gugup dan takut, (4) siswa juga tidak mendengarkan saat kelompok lain menyampaikan presentasi, siswa sibuk melakukan kegiatan, seperti berbicara/bercanda dengan temannya. Upaya yang guru lakukan agar siswa fokus kembali pada pembelajaran adalah menegur siswa dengan cara memanggil nama siswa untuk memperhatikan kelompok yang presentasi atau guru akan meminta siswa untuk menyimpulkan apa yang disampaikan temannya di depan kelas.

Hal di atas didukung dari hasil wawancara yang telah dilakukan dengan guru, diketahui bahwa masih ditemukan siswa yang tidak ikut bertanggung jawab atas tugas kelompoknya, sulit untuk dikondisikan, dan siswa masih takut untuk menjawab pertanyaan dan tampil di depan kelas. Sejalan dengan hasil wawancara dari enam orang siswa kelas V yang dipilih secara acak, diketahui siswa pertama mengatakan bahwa saat pembelajaran di kelas teman-temannya sangat sulit diatur dan hanya ada 10 orang dari temannya selalu aktif menjawab pernyataan yang guru ajukan dan tampil di depan kelas. Siswa kedua juga mengatakan bahwa teman-temannya tidak tertib, dalam kelompoknya hanya dia dan dua orang teman lainnya yang selalu menyelesaikan perkerjaan kelompok dari guru, sedangkan siswa lainnya hanya menunggu jawaban. Siswa ketiga mengatakan tidak banyak dari teman kelasnya yang aktif saat pembelajaran, dia termasuk salah satu siswa yang aktif saat pembelajaran. Siswa keempat mengatakan bahwa tiga orang temannya tidak ikut berdiskusi saat guru memberikan tugas kelompok. Dua orang siswa lainnya mengatakan hal yang sama dengan siswa pertama. 
Hal-hal yang diidentifikasi menjadi penyebab keterampilan sosial siswa kurang, yaitu (1) jumlah siswa dalam satu kelas cukup banyak, yaitu 32 orang, sedangkan jumlah maksimal siswa dalam satu kelas adalah 28 orang sehingga guru mengalami kesulitan mengondisikan siswa untuk fokus pada pembelajaran, (2) pemanfaatan media dan model pembelajaran yang bervariasi masih jarang dilakukan oleh guru, (3) kurangnya kesiapan siswa untuk memulai pembelajaran, (4) materi yang dirasa cukup sulit hingga membuat siswa takut, dan (5) kurangnya fokus siswa pada pembelajaran.

Berdasarkan uraian di atas dapat dikatakan keterampilan sosial siswa masih kurang. Permasalahan yang muncul yakni kurangnya keterampilan sosial akan berpengaruh pada keberhasilan belajar siswa. Keterampilan sosial merupakan perilaku atau keterampilan yang menstimulasi interaksi positif siswa dengan lingkungannya dan orang lain, diantaranya menunjukkan sikap empati, ikut serta dalam kegiatan kelompok, berkomunikasi, kemurahan hati, saling menolong, bernegosiasi, dan memecahkan masalah (Lynch \& Simpson, 2010). Keterampilan sosial juga dapat didefinisikan sebagai perilaku tertentu yang ditunjukkan seseorang untuk berhasil dalam tugas sosial, tugas sosial dapat mencakup hal-hal seperti berada pada kelompok sebaya, memulai dan pembertahankankan percakapan, bermain dan berteman dengan teman sebaya (Gresham, Elliott, Cook, Vance, \& Kettler, 2010).

Keterampilan sosial dibutuhkan siswa untuk beradaptasi di lingkungan sekolah dan masyarakat. Sukses dalam pembelajaran mengharuskan siswa untuk berinteraksi secara dekat dengan guru dan teman sejawatnya, selain untuk kepentingan umum siswa dalam interaksi sehari-hari, keterampilan sosial juga dapat berdampak besar pada kemampuan siswa untuk berhasil dalam lingkungan akademik (Steedly, Schwartz, Levin, \& Luke, 2008). Adapun lima aspek-aspek keterampilan sosial siswa tingkat sekolah dasar dan menengah diantaranya kerjasama, ketegasan, tanggung jawab, empati, dan pengendalian diri (Gresham, Elliott, Vance, \& Cook, 2011).

Pemilihan model kooperatif merupakan salah satu usaha untuk meningkatkan keterampilan sosial dengan menciptakan pembelajaran yang menarik dan menyenangkan. Pembelajaran kooperatif merupakan pembelajaran yang dilakukan dengan siswa bekerjasama dan bertanggung jawab atas pembelajaran orang lain sebagaiman pembelajaran mereka sendiri (Hanna, David, \& Francisco, 2010). Permasalahan terkait sosial dalam pembelajaran dapat diatasi dengan menerapkan model pembelajaran kooperatif (Kagan \& Kagan, 2009). Penerapan model Find Someone Who (FSW) dan Quiz-Quiz Trade (QQT) mampu memberikan solusi karena kedua model ini dapat meningkatkan keterampilan sosial. Model FSW dan QQT merupakan model pembelajaran yang berfokus pada siswa dan melibatkan seluruh siswa di kelas untuk saling berinteraksi dan saling mendukung satu sama lain.

Model FSW adalah sebuah model pembelajaran yang mengikut sertakan semua siswa di kelas dengan cara membentuk dan mencari-cari pasangan yang mengetahui jawaban, mengajukan pertanyaan secara bergantian, kemudian siswa akan membandingkan jawaban yang diperolehnya (Kagan \& Kagan, 2009). Peneliti melakukan modifikasi pada model FSW tanpa merubah sintak aslinya yaitu dengan menambah kegiatan diskusi. Modifikasi dilakukan berdasarkan struktur fungsinya yaitu membangun kelas dan pengetahuan, serta, karena tidak adanya kegiatan diskusi pada sintak dan peneliti merasa perlu adanya kegiatan diskusi setelah akhir sintak yang dilakukan secara klasikal dan dipimpin oleh guru. Modifikasi dilakukan dengan menambah satu sintak tanpa mengubah keaslian model yaitu siswa melakukan kegiatan diskusi di kelas. Kegiatan diskusi dilakukan setelah siswa membandingkan jawaban yang mereka peroleh dalam kelompok, kegiatan diskusi diikuti oleh seluruh siswa dengan guru sebagai pemimpin diskusi. Model FSW mampu meningkatkan hasil belajar pada muatan IPS dan keterampilan sosial siswa berdasarkan hasil penelitian yang menunjukkan ada peningkatan secara signifikan pada setiap siklusnya (Marlina, Soetjipto, \& Hadi, 2016).

Model QQT adalah sebuah model pembelajaran yang mengikutsertakan siswa secara berpasangan, yakni siswa memberi pertanyaan kepada pasangannya dan sebaliknya, apabila siswa menjawab salah maka pasangannya bertugas untuk mengajarkan atau memperbaikinya, siswa bertukar kartu kemudian mengulangi tahapan dengan siswa yang berbeda (Kagan \& Kagan, 2009). Hasil penelitian menunjukan implementasi QQT dapat memperbaiki hasil belajar dan keterampilan sosial siswa dengan adanya kenaikan persentase secara signifikan pada setiap siklusnya (Purwaningrum, Soetjipto, \& Untari, 2017). Penerapan model QQT di kelas V tidak hanya dapat memperbaiki keterampilan sosial, juga dapat memperbaiki hasil belajar kognitif pada muatan IPS (Nurdianasari, Hanurawan, Soetjipto, 2017). Berdasarkan penelitian oleh peneliti sebelumnya, alasan kedua model ini terapkan secara bergantian karena kedua model sama-sama dapat meningkatkan keterampilan sosial siswa, masing-masing model memiliki kelebihan dan kekurangan, agar siswa tidak bosan dan lebih tertarik pada pembelajaran.

\section{METODE}

Penelitian Tindakan Kelas digunakan sebagai metode dalam penelitian ini. Penelitian Tindakan Kelas dimaksud untuk menyelesaikan permasalahan yang terjadi di kelas. Penelitian dilakukan secara bersiklus hingga mencapai kriteria keberhasilan. Penelitan ini dilaksanakan di SDN Sumbersari 1 Malang. Subjek terdiri dari 11 siswa laki-laki dan 21 siswa perempuan. Waktu penelitian dilaksanakan pada bulan Februari-Maret 2019.

Indikator keterampilan sosial, meliputi (1) kerjasama; (2) ketegasan; (3) tanggung jawab; (4) empati; (5) pengendalian diri. Observasi dan angket digunakan sebagai teknik pengumpulan data. Observasi keterampilan sosial dilakukan oleh dua orang observar yaitu wali kelas V dan mahasiswa Pascasarjana Pendidikan Dasar. Angket diberikan pada akhir siklus. Angket berjumlah 35 butir pernyataan yang dikembangkan dari lima indikator keterampilan sosial. Analisis data menggunakan analisis 
deskriptif untuk mengetahui keterampilan sosial siswa melalui penerapan model Modified FSW dan QQT. Kriteria keberhasilan penelitian tindakan ini mencapai rata-rata minimal $\geq 80 \%$.

\section{HASIL}

Penelitian ini dilaksanakan sebanyak dua siklus. Masing-masing siklus terdiri dari lima pertemuan. Pertemuan pertama dan ketiga menggunakan model Modified FSW, pertemuan kedua dan keempat menggunakan model QQT, dan pertemuan lima siswa mengisi angket keterampilan sosial. Penerapan masing-masing siklus memiliki langkah yang sama, yaitu perencanaan, pelaksanaan, pengamatan, dan refleksi. Kegiatan pembelajaran terlaksana dengan sangat baik. Hasil observasi keterampilan sosial siswa pada siklus I ditunjukkan pada tabel 1. Data keterampilan sosial juga diperoleh melalui angket yang diisi oleh siswa di akhir pertemuan siklus. Hasil angket keterampilan sosial siswa pada siklus I ditunjukkan pada tabel 2.

Tabel 1. Hasil Observasi Keterampilan Sosial Siswa Siklus I

\begin{tabular}{clll}
\hline No. & Aspek Penilaian & Persentase & Kriteria \\
\hline 1 & Kerjasama & $76,8 \%$ & Baik \\
2 & Ketegasan & $71,7 \%$ & Baik \\
3 & Tanggung Jawab & $81,3 \%$ & Sangat Baik \\
4 & Empati & $76,8 \%$ & Baik \\
5 & Pengendalian Diri & $74,6 \%$ & Baik \\
\hline Rata-Rata Persentase Observasi & $76,2 \%$ & Baik \\
Keterampilan Sosial Siswa Siklus I & & \\
\hline
\end{tabular}

Tabel 2. Hasil Angket Keterampilan Sosial Siswa Siklus I

\begin{tabular}{ccc}
\hline Data & Persentase & Kriteria \\
\hline Hasil Angket Klasikal & $81,0 \%$ & Sangat Baik \\
\hline
\end{tabular}

Data observasi keterampilan sosial siswa menunjukkan kriteria baik dengan persentase 76,2\%. Sedangkan, angket menunjukkan kriteria sangat baik dengan persetase 81,0\%. Perolehan data observasi keterampilan sosial siswa telah memenuhi kriteria baik namun belum mencapai kategori keberhasilan. Maka, perlu adanya perbaikan dengan melaksanakan siklus selanjutnya.

Perbaikan yang diterapkan berdasarkan hasil refleksi pada siklus pertama, meliputi (1) pembelajaran dengan model QQT dilakukan di luar kelas; (2) memberi motivasi kepada siswa untuk aktif dan saling bekerjasama dalam kegiatan di kelas; (3) meminta siswa menjaga dan mengondisikan kelas agar selalu kondusif. Hasil observasi keterampilan sosial dan data angket keterampilan sosial pada siklus II ditunjukkan pada tabel 3 dan 4.

Tabel 3. Hasil Observasi Keterampilan Sosial Siswa Siklus II

\begin{tabular}{clll}
\hline No. & Aspek Penilaian & Persentase & Kriteria \\
\hline 1 & Kerjasama & $86,5 \%$ & Sangat Baik \\
2 & Ketegasan & $82,2 \%$ & Sangat Baik \\
3 & Tanggung Jawab & $86,1 \%$ & Sangat Baik \\
4 & Empati & $86,9 \%$ & Sangat Baik \\
5 & Pengendalian Diri & $80,7 \%$ & Sangat Baik \\
\hline \multicolumn{2}{l}{ Rata-Rata Persentase Observasi } & $84,5 \%$ & Sangat Baik \\
\multicolumn{2}{l}{ Keterampilan Sosial Siswa Siklus II } & & \\
\hline
\end{tabular}

Tabel 4. Hasil Angket Keterampilan Sosial Siswa Siklus II

\begin{tabular}{ccc}
\hline Data & Persentase & Kriteria \\
\hline Hasil Angket Klasikal & $85,2 \%$ & Sangat Baik \\
\hline
\end{tabular}

Data hasil observasi keterampilan sosial siswa siklus II menunjukkan kriteria sangat baik dengan persentase $84,5 \%$, sedangkan data hasil angket menunjukkan juga kriteria sangat baik dengan persetase $85,2 \%$. Kedua data yang diperoleh melalui observasi dan angket keterampilan sosial siswa telah mencapai kriteria sangat baik dan kriteria keberhasilan yang telah ditentukan yaitu $\geq 80 \%$. Peningkatan keterampilan sosial siswa kelas V SDN Sumbersari 1 Malang terlihat pada gambar 1 dan 2. 


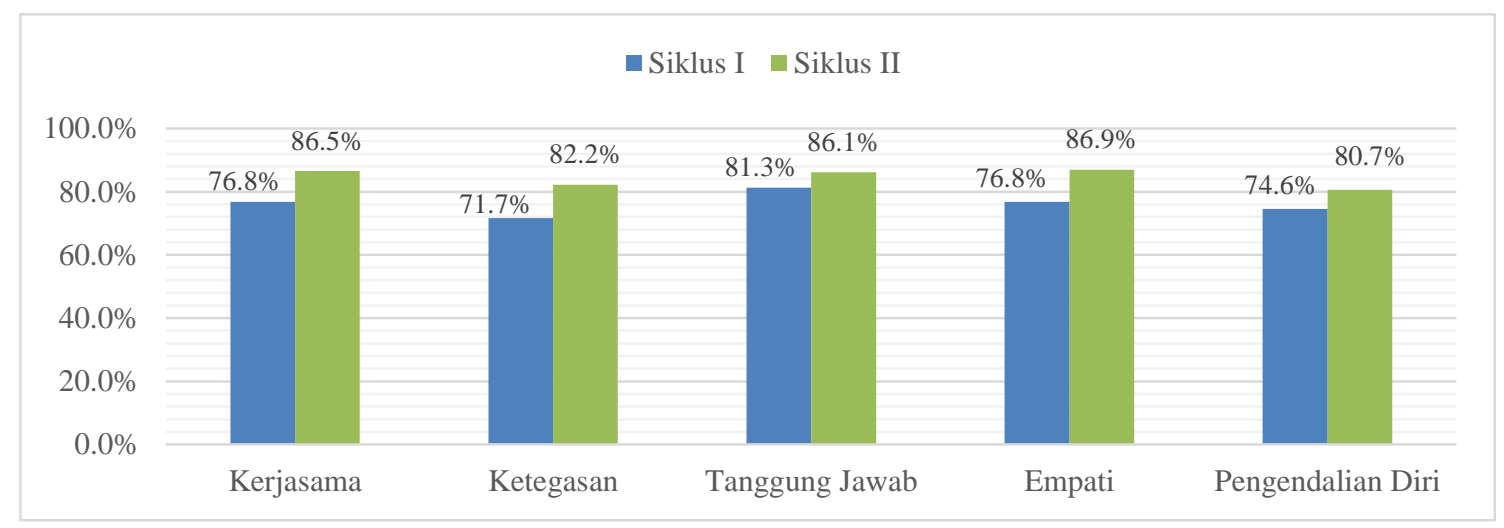

Gambar 1. Diagram Peningkatan Observasi Keterampilan Sosial Siswa

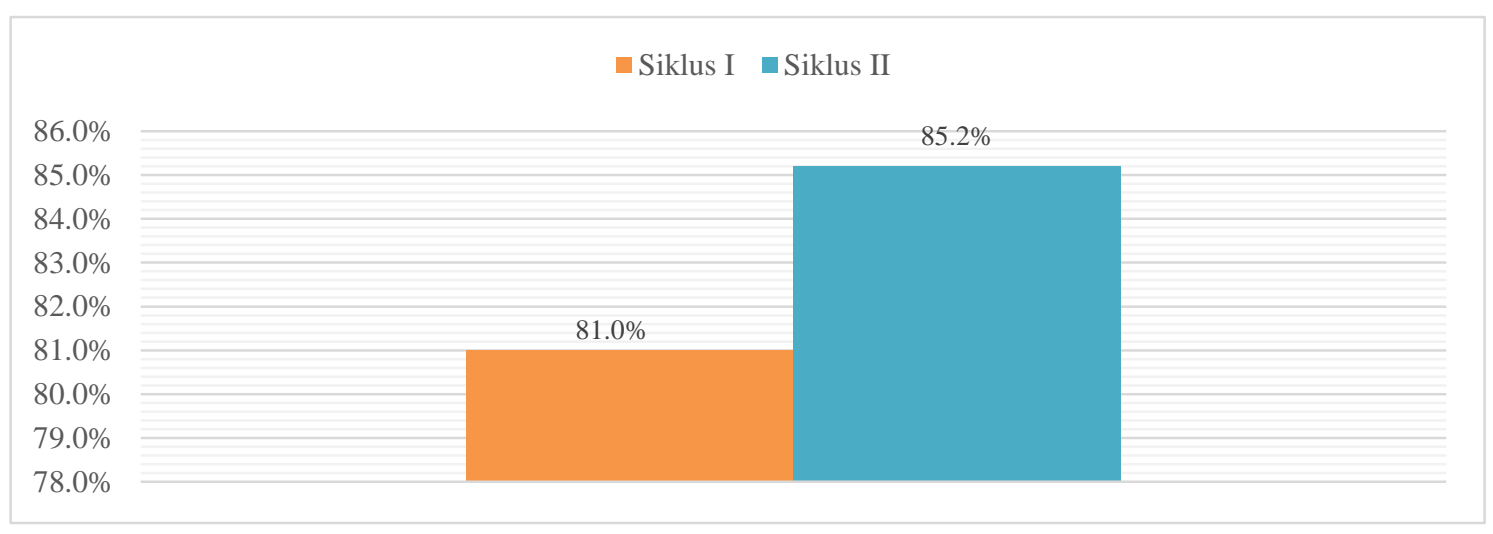

Gambar 2. Diagram Peningkatan Angket Keterampilan Sosial Siswa

\section{PEMBAHASAN}

Pembelajaran dengan model Modified FSW dan QQT dapat meningkatkan keterampilan sosial siswa kelas V. Pelaksanaan pembelajaran pada setiap siklusnya juga terlaksana dengan baik. Aspek keterampilan sosial yang diamati, meliputi kerjasama, ketegasan, tanggung jawab, empati, dan pengendalian diri. Hasil observasi yang diperoleh selama proses pembelajaran model Modified FSW dan QQT yaitu siswa fokus pada pembelajaran, menunjukkan sikap saling membantu, saling mengajari satu sama lain, bertanggung jawab atas tugas yang guru berikan, berinteraksi dengan siswa lainnya, siswa juga terlihat antusias mengikuti pembelajaran, siswa berani mengungkapkan pendapatnya pada kegiatan diskusi baik pada diskusi kelompok maupun secara klasikal.

Model FSW memberi dampak positif, yakni siswa saling bekerja sama untuk memecahkan masalah dalam pembelajaran, adanya interaksi yang positif antar siswa, siswa berani mengutarakan pendapat ketika memiliki perbedaan pendapat dengan siswa lainnya (Nurhaniyah, Soetjipto, \& Hanurawan, 2015). Hal tersebut diperkuat oleh penelitian yang menyatakan adanya peningkatan keterampilan soisal, juga hasil belajar siswa setelah tindakan dengan menerapkan model FSW, data tersebut diperoleh melalui observasi, wawancara, tes, dan angket (Marlina, Soetjipto, \& Hadi, 2016). Sama halnya dengan model Modified FSW, model QQT memberi siswa pengalaman belajar yang baik dan menyenangkan (Nurdianasari, Hanurawan, Soetjipto, 2017). Melalui model QQT siswa dapat belajar bersama dengan teman-temannya, mendengarkan pertanyaan dan jawaban masing-masing, tidak mencela jawaban teman, dan siswa juga memiliki tanggung jawab untuk berbagi pengetahuan atau mengajar teman dan bertanggung jawab atas diri mereka sendiri (Purwaningrum et al., 2017).

Selama pelaksanaan pembelajaran dengan model Modified FSW terdapat beberapa kelebihan dan kekurangan. Adapun kelebihannya, yakni (1) pembelajaran jadi menyenangkan, (2) siswa dapat saling membantu memecahkan masalah/soal, (3) siswa diberi kesempatan untuk menyampaikan pendapat, dan (4) siswa dapat berinteraksi dengan seluruh siswa di kelas. Sementara kekurangannya, yaitu (1) kelas menjadi gaduh dan (2) pada kegiatan kelompok yaitu membandingkan jawaban kurang maksimal. Kelebihan dan kekurangan di atas juga dijelaskan oleh peneliti sebelumnya (Kurnia, Degeng, \& Soetjipto, 2017). 
Kelebihan model QQT, yaitu (1) melalui kegiatan tanya jawab menggunakan kartu soal, siswa lebih bersemangat saat pembelajaran, (2) siswa dapat mengingat informasi penting yang diperoleh dengan cepat, dan (3) memberi pengalaman belajar yang menyenangkan bagi siswa. Sementara itu, kekurangan model OOT, yaitu (1) pembelajaran efektif dilakukan dengan jumlah siswa genap, jika jumlah siswa di kelas ganjil guru perlu mempersiapkan alternatif pembelajaran jika terjadi hal tersebut dan (2) model ini hanya dapat diterapkan pada materi pembelajaran tertentu.

Simpulan penjelasan diatas bahwa model Modified FSW dan QQT memberi dampak positif terhadap keterampilan sosial siswa. Hal ini juga berdasarkan hasil observasi keterampilan sosial siswa oleh dua orang observer yang menunjukkan peningkatan sebesar $76,2 \%$ pada siklus I dan $84,4 \%$ pada siklus II dengan kriteria baik dan sangat baik. Sementara itu, hasil angket yang diisi langsung oleh siswa menunjukkan kriteria sangat baik yaitu sebesar $81,0 \%$ pada siklus I dan $85,2 \%$ pada siklus II.

\section{SIMPULAN}

Penerapan model Modified FSW dan QQT dapat meningkatkan keterampilan sosial siswa kelas V di SDN Sumbersari 1 Malang. Melalui hasil observasi dan angket keterampilan sosial siswa selama dua siklus pada lima aspek keterampilan sosial. Hasil observasi keterampilan sosial siswa yang diisi oleh dua orang observer pada siklus I sebesar 76,2\% dan siklus II sebesar $84,5 \%$. Peningkatan rata-rata persentase observasi keterampilan sosial antar kedua siklus sebersar $8,3 \%$, sedangkan, hasil angket keterampilan sosial yang diisi oleh siswa pada siklus I sebesar $81,0 \%$ dan siklus II sebesar $85,2 \%$. Penigkatan persentase angket keterampilan sosial pada antara kedua siklus sebesar 4,2\%.

Kegiatan proses pembelajaran model Modified FSW dan model QQT dapat dilakukan di luar kelas, kedua model juga dapat digunakan dalam meningkatkan hasil belajar. Oleh karena itu, guru perlu merancang alternatif sintak jika ada siswa yang tidak hadir dan pemilihan model disesuaikan dengan materi.

\section{DAFTAR RUJUKAN}

Gresham, F. M., Elliott, S. N., Cook, C. R., Vance, M. J., \& Kettler, R. (2010). Cross-Informant Agreement for Ratings for Social Skill and Problem Behavior Ratings: An Investigation of the Social Skills Improvement System-Rating Scales. Psychological Assessment, 22(1), 157-166. https://doi.org/10.1037/a0018124

Gresham, F. M., Elliott, S. N., Vance, M. J., \& Cook, C. R. (2011). Comparability of the Social Skills Rating System to the Social Skills Improvement System: Content and Psychometric Comparisons Across Elementary and Secondary Age Levels. School Psychology Quarterly, 26(1), 27-44. https://doi.org/10.1037/a0022662

Hanna, D., David, I., \& Francisco, B. (2010). Educational Research and Innovation The Nature of Learning Using Research to Inspire Practice. OECD Publishing, 340.

Kagan, S., \& Kagan, M. (2009). Why Do We Need Cooperative Learning? In Kagan Cooperative Learning.

Kurnia, N., Degeng, I. N. S., \& Soetjipto, B. E. (2017). The Implementation of Find Someone Who and Two Stay Two Stray Models to Improve Students' Self-Efficacy and Social Studies Learning Outcomes. IOSR Journal of Research \& Method in Education (IOSRJRME), 07(03), 66-70. https://doi.org/10.9790/7388-0703036670

Lynch, S. A., \& Simpson, C. G. (2010). Social Skills: Laying the Foundation for Success. Dimensions of Early Childhood, $38(2), 1-121$.

Marlina, L., Soetjipto, B. E., \& Hadi, S. (2016). The Implementation of Rally Coach and Find Someone Who Models to Enhance Social Skill and Social Studies Learning Outcomes. IOSR Journal of Research \& Method in Education, 6(3), 86-92. https://doi.org/10.9790/7388-0603018692

Nurdianasari, N., Hanurawan, F., \& Soetjipto, B. E. (2017). The Implementation of Quiz-Quiz-Trade and Fan-N-Pick Learning Model to Enhance Social Skills and Cognitive Learning Outcome of Social Studies. International Journal of Humanities and Social Science Invention, 6(6), 81-85.

Nurhaniyah, B., Soetjipto, B. E., \& Hanurawan, F. (2015). The Implementation of Collaborative Learning Model "Find Someone Who and Flashcard Game" to Enhance Social Studies Learning Motivation for the Fifth Grade Students. Journal of Education and Practice, 6(17), 166-171.

Purwaningrum, M. D., Soetjipto, B. E., \& Untari, S. (2017). The Implementation of Cooperative Learning Model Quiz-Quiz Trade and Inside-Outside Circle to Improve the Students Social Skills and Learning Outcomes. International Journal of Academic Research in Business and Social Sciences, 7(6), 473-486. https://doi.org/10.6007/ijarbss/v7-i6/3005 